\section{OPEN ACCESS}

Edited by:

Firas H. Kobeissy,

University of Florida, United States

Reviewed by:

Andrew I.R. Maas,

Antwerp University Hospital, Belgium

Bridgette D. Semple,

Monash University, Australia

*Correspondence:

Jean-Charles Sanchez

Jean-Charles.Sanchezunige.ch

†These authors have contributed equally to this work

Specialty section: This article was submitted to Neurotrauma

a section of the journal

Frontiers in Neurology

Received: 31 January 2020 Accepted: 14 April 2020 Published: 02 June 2020

Citation:

Lagerstedt L, Azurmendi L, Tenovuo O, Katila AJ, Takala RSK,

Blennow K, Newcombe VFJ, Maanpää H-R, Tallus J, Hossain I, Gils Mv, Menon DK, Hutchinson PJ,

Zetterberg $\mathrm{H}$, Posti JP and

Sanchez J-C (2020) Interleukin 10 and Heart Fatty Acid-Binding Protein as Early Outcome Predictors in Patients With Traumatic Brain Injury.

Front. Neurol. 11:376.

doi: 10.3389/fneur.2020.00376

\title{
Interleukin 10 and Heart Fatty Acid-Binding Protein as Early Outcome Predictors in Patients With Traumatic Brain Injury
}

\begin{abstract}
Linnéa Lagerstedt ${ }^{1 \dagger}$, Leire Azurmendi ${ }^{1 \dagger}$, Olli Tenovuo ${ }^{2,3}$, Ari J. Katila ${ }^{4}$, Riikka S. K. Takala ${ }^{4}$, Kaj Blennow ${ }^{5}$, Virginia F. J. Newcombe ${ }^{6}$, Henna-Riikka Maanpää ${ }^{2,3,7}$, Jussi Tallus ${ }^{3}$, Iftakher Hossain ${ }^{2,3,7}$, Mark van Gils ${ }^{8}$, David K. Menon ${ }^{6}$, Peter J. Hutchinson ${ }^{9,10,11,}$ Henrik Zetterberg ${ }^{5,12,13}$, Jussi P. Posti ${ }^{2,3,7 \dagger}$ and Jean-Charles Sanchez ${ }^{1 *+}$

${ }^{1}$ Department of Specialities of Internal Medicine, Faculty of Medicine, University of Geneva, Geneva, Switzerland, ${ }^{2}$ Turku Brain Injury Centre, Turku University Hospital, Turku, Finland, ${ }^{3}$ Department of Clinical Neurosciences, University of Turku, Turku, Finland, ${ }^{4}$ Perioperative Services, Intensive Care Medicine and Pain Management, Turku University Hospital and University of Turku, Turku, Finland, ${ }^{5}$ Department of Psychiatry and Neurochemistry, Institute of Neuroscience and Physiology, Sahlgrenska Academy at the University of Gothenburg, Mölndal, Sweden, ${ }^{6}$ Division of Anaesthesia, Department of Medicine, University of Cambridge, Addenbrooke's Hospital, Cambridge, United Kingdom, ${ }^{7}$ Division of Clinical Neurosciences, Department of Neurosurgery, Turku University Hospital Turku, Turku, Finland, ${ }^{8}$ Knowledge Intensive Products and Services, VTT Technical Research Centre of Finland Ltd, Tampere, Finland, ${ }^{9}$ Division of Neurosurgery, Department of Clinical Neurosciences, University of Cambridge, Addenbrooke's Hospital, Cambridge, United Kingdom, ${ }^{10}$ National Institute for Health Research, Cambridge BRC, Cambridge, United Kingdom, "1 Royal College of Surgeons of England, London, United Kingdom, ${ }^{12}$ UK Dementia Research Institute at UCL, London, United Kingdom, ${ }^{13}$ Department of Neurodegenerative Disease, UCL Institute of Neurology, London, United Kingdom
\end{abstract}

Background: Patients with traumatic brain injury (TBI) exhibit a variable and unpredictable outcome. The proteins interleukin 10 (IL-10) and heart fatty acid-binding protein $(\mathrm{H}-\mathrm{FABP})$ have shown predictive values for the presence of intracranial lesions.

Aim: To evaluate the individual and combined outcome prediction ability of $\mathrm{IL}-10$ and $\mathrm{H}$-FABP, and to compare them to the more studied proteins $\mathrm{S100} \beta$, glial fibrillary acidic protein (GFAP), and neurofilament light (NF-L), both with and without clinical predictors.

Methods: Blood samples from patients with acute TBI (all severities) were collected $<24 \mathrm{~h}$ post trauma. The outcome was measured $>6$ months post injury using the Glasgow Outcome Scale Extended (GOSE) score, dichotomizing patients into: (i) those with favorable (GOSE $\geq 5$ )/unfavorable outcome (GOSE $\leq 4$ ) and complete (GOSE = 8)/incomplete (GOSE $\leq 7$ ) recovery, and (ii) patients with mild TBI (mTBI) and patients with TBls of all severities.

Results: When sensitivity was set at 95-100\%, the proteins' individual specificities remained low. H-FABP showed the best specificity (\%) and sensitivity (100\%) in predicting complete recovery in patients with mTBI. IL-10 had the best specificity $(50 \%)$ and sensitivity (96\%) in identifying patients with favorable outcome in patients with TBls of all severities. When individual proteins were combined with clinical parameters, a model including H-FABP, NF-L, and ISS yielded a specificity of $56 \%$ and a sensitivity of $96 \%$ in predicting complete recovery in patients with $\mathrm{mTBI}$. 
In predicting favorable outcome, a model consisting IL-10, age, and TBI severity reached a specificity of $80 \%$ and a sensitivity of $96 \%$ in patients with TBls of all severities.

Conclusion: Combining novel TBI biomarkers H-FABP and IL-10 with GFAP, NF-L and $\mathrm{S} 100 \beta$ and clinical parameters improves outcome prediction models in TBI.

Keywords: biomarker, heart fatty-acid binding protein, interleukin 10, panel, protein, outcome, traumatic brain injury

\section{INTRODUCTION}

Patients with TBI may suffer from different levels and persistence of cognitive, behavioral, emotional, and physical impairments $(1,2)$. These impairments are frequent in patients with moderate and severe TBI, while, in cases of mild TBI (mTBI), most of the patients recover within weeks to months after the injury. However, a significant subgroup of patients with mTBI shows incomplete recovery (3-5). Despite these post-traumatic symptoms, structural brain damage in this population is often not seen using current clinical imaging modalities. The problem is significant worldwide, as mTBI accounts for $80-90 \%$ of all cases with TBI (6).

Different blood-based biomarkers have been suggested as outcome predictors of TBI to improve clinicians' abilities to optimize clinical care. Among the most studied biomarkers are the astroglial proteins $\mathrm{S} 100$ calcium-binding protein $\mathrm{B}$ $(\mathrm{S} 100 \beta)$, glial fibrillary acidic protein (GFAP), and the axonal protein neurofilament light (NF-L) (7-13). Other proteins, such as the anti-inflammatory protein interleukin 10 (IL-10) and the brain injury marker heart fatty acid-binding protein $(\mathrm{H}-$ FABP), have recently gained in interest as diagnostic tools for TBI, but little is known about their abilities as outcome predictors $(14,15)$.

To date, most biomarker studies have investigated proteins' individual prediction abilities. Considering the pathophysiological complexity of TBI, single biomarkers tend to have low prediction capacities, and they may therefore not be optimal for clinical use (16). To improve the accuracy, combining several biomarkers together or combining biomarker(s) with clinical parameters have been suggested, thus producing models of several predictive markers $(16,17)$. These kinds of models have already shown to significantly increase the predictive power compared to single markers in different diseases, such as aneurysmal subarachnoid hemorrhage, lung cancer, and sleeping sickness (18-21). Recent studies have also highlighted the beneficial use of panels as diagnostic tools for mTBI $(22,23)$ and for predicting the need for acute head imaging following TBI (24). Furthermore, combining inflammatory proteins together with brain-derived ones may improve the ability to predict outcome after TBI $(25,26)$.

The aim of the present study was to compare the proteins IL-10 and H-FABP to the well-studied proteins S100 $\beta$, GFAP, and NF-L for their individual ability to predict patients who will have favorable long-term outcome analyzing patients on a clinically meaningful allocation basis: patients with mTBI and patients with TBIs of all severities. In order to demonstrate the added value of blood biomarkers in addition to clinical variables, we analyzed the biomarkers in isolation and with clinical variables recorded upon admission. Furthermore, combinations of predictive markers were evaluated in an attempt to increase this prediction ability.

\section{MATERIALS AND METHODS}

\section{Study Population and Clinical Variables}

In this single-center study, patients were recruited at Turku University Hospital (a tertiary care university hospital with a combined primary and tertiary care emergency department) in Finland between the years 2011-2013. All the consecutive patients with TBI were evaluated for eligibility to be recruited in the study by the research team between 8 a.m. to 10 p.m. To be included in the study, the following inclusion criteria needed to be fulfilled; age $\geq 18$ years, hospital admission within $24 \mathrm{~h}$ after trauma, clinical diagnosis of a TBI with an indication for a head computed tomography (CT) scan according to the NICE criteria (27) as judged by an emergency physician on call, and outcome data at 6-12 months after injury had to be available. Exclusion criteria were penetrating or blast-induced injury, chronic subdural hematoma, inability to live independently due to a previous brain disease, no performed CT scan, or no written consent.

The ethical review board of Hospital District of South-West Finland approved the study protocol (decision 68/180/2011). Written informed consent was obtained from all participants or their legal representatives prior to inclusion.

The outcomes were assessed by single experienced neurologist (OT) using the Glasgow Outcome Scale Extended (GOSE) (28). The total injury burden was assessed with Injury Severity Score (ISS) (29).

\section{Head Imaging and Traumatic Brain Injury Severity Classifications}

Head CT scans were classified according to the Marshall classification system (30). Neuroradiologists at the Turku University Hospital and a senior neurosurgeon (JPP) doubleread the CT scans.

In addition to using the lowest Glasgow Coma Scale (GCS) score before possible intubation, either at the scene of accident or emergency department (31), TBI severity was also classified using 
an aggregate covariate combining the lowest GCS and the length of post-traumatic amnesia ${ }^{1}$.

\section{Protein Measurement}

Serum samples were drawn within $24 \mathrm{~h}$ after trauma. However, as these different time points did not appear to correlate with biomarker levels, all of them were considered as a common time point. Only admission samples were assessed. After obtaining the blood samples, the samples were centrifuged and stored at $-70{ }^{\circ} \mathrm{C}$. The proteins GFAP and NF-L were measured using the Human Neurology 4-plex A assay (N4PA) on HD-1 single molecule array (Simoa) device from Quanterix (Lexington, MA, USA). The lower limit of quantification (LLoQ) for each kit was $0.104 \mathrm{pg} / \mathrm{mL}$ for NF-L and $0.221 \mathrm{pg} / \mathrm{mL}$ for GFAP. The protein $\mathrm{S} 100 \beta$ was measured using the EZHS100B-33K kit from Millipore (Millipore, Billerica, MA, USA) with an LloQ of $2.74 \mathrm{pg} / \mathrm{mL}$. H-FABP and IL-10 were analyzed using the K151HTD and K151QUD kits, respectively, Meso Scale (Meso Scale Diagnostics, Rockville, MD, USA). The LloQ for HFABP was $0.137 \mathrm{ng} / \mathrm{mL}$ and for IL-10 $0.298 \mathrm{pg} / \mathrm{mL}$. All proteins were measured according to manufacturers' recommendations by board-certified laboratory technicians who were blinded to clinical data.

\section{Statistical Analysis}

Statistical analyses were performed to evaluate the proteins' outcome prediction ability defined by the GOSE score. The patients were dichotomized in two different groups: (a) the first one included TBI patients of all severities (worst GCS $3-15, n=88$ ), while the second one (b) included only the subgroup of mTBI (worst GCS 13-15, $n=49$ ) patients. The GOSE was dichotomized into (a) 1-4 for unfavorable outcome or 5-8 for favorable outcomes for all severity patients and (b) 1-7 for incomplete recovery or 8 for complete recovery for mTBI patients. These dichotomizations were chosen because the favorable/unfavorable outcome is relevant for TBIs in general (especially moderate-severe TBIs) and complete/incomplete for those with mTBI. Non-parametric tests were used because all proteins were non-normally distributed, as indicated by the Kolmogorov-Smirnov test $(p<0.05)$. Therefore, to evaluate the proteins' differences between groups, the Mann-Whitney $\mathrm{U}$ test was performed using IBM SPSS software, version 24.0 (SPSS Inc., Chicago, IL, USA). The proteins' outcome prediction capacities were evaluated using the partial area under a receiver operating characteristic cure (pAUC), which allowed us to focus only in the interest region of the ROC curve. Analysis were computed using TIBCO Spotfire $\mathrm{S}^{\circledR}{ }^{\circledR}$ version 8.2 software (TIBCO Software Inc., Palo Alto, CA, USA). Model selections were done using the PanelomiX toolbox based on the iterative combination of biomarkers/variables and thresholds method (ICBT) (32). To make the process faster, several biomarkers (HFABP, IL-10, S100 $\beta$, NF-L, and GFAP)/variables (age, Marshall grade, Injury Severity Score, Severity, and GCS) were tested together. PanelomiX used the random forest method to select the different thresholds. Cross validation and ROC analysis

${ }^{1}$ https://www.healthquality.va.gov/guidelines/Rehab/mtbi/ mTBICPGFullCPG50821816.pdf were used to evaluate the performance of the model. In this manuscript, a maximum number of three biomarkers or clinical parameters in each model were investigated. The PanelomiX tool established the best cut-off for each single biomarker, and the best combinations were investigated when the sensitivity was set at $95-100 \%$ in order to reduce the false negative cases.

\section{RESULTS}

\section{Study Population}

A total of 88 TBI patients with blood samples available within 24 from the time of injury were included in this study, and $69 \%$ of the patients were male. The most common causes of trauma were falls and traffic accidents. The distributions of severity, imaging findings, and outcome are shown in Table 1.

\section{Complete Recovery - Patients With mTBI}

We first investigated the proteins' individual capacities to predict complete recovery in patients with mTBI. All these proteins tended to be higher in patients with incomplete recovery (GOSE $\leq 7, n=24$ ) compared to those with complete recovery (GOSE $8, n=25$ ), although these findings were without significance. The proteins were investigated when the sensitivity was set at $95-100 \%$. The individual specificities remained low. The best performing protein was $\mathrm{H}$-FABP, reaching $4 \%$ specificity and $100 \%$ sensitivity. NF-L and S100 $\beta$ had somewhat higher specificities of $12 \%$ but lower sensitivities of $96 \%$ (Table 2 ).

Next, combinations of proteins to increase the ability to predict complete recovery were evaluated. The best two-protein panel was a combination of $\mathrm{H}-\mathrm{FABP}$ and NF-L, reaching a specificity of $40 \%$ and sensitivity of $96 \%$, thus resulting in a $36-$ percentage point increase in specificity compared to the best performing single protein $\mathrm{H}-\mathrm{FABP}$. A panel comprising three proteins-H-FABP, GFAP, and NF-L-was further capable of increasing the specificity to $44 \%$ with $96 \%$ sensitivity (Table 3 ).

Combining individual proteins with clinical parameters was also evaluated to predict complete recovery (Table 3). Combination of H-FABP, the most specific molecule in isolation, with clinical parameters showed an improved performance over proteins alone. Maintaining a value of $96 \%$ sensitivity, the combination of H-FABP, NF-L, and TBI severity reached a specificity value of $56 \%$, which is far better than for H-FABP alone (Table 3). The individual outcome prediction capacities of clinical parameters are presented in Supplementary Table 1.

\section{Favorable Outcome - Patients With TBIs of All Severities}

H-FABP, IL-10, S100 $\beta$, NF-L, and GFAP were evaluated for their individual capacities to predict favorable outcome in patients with TBIs of all severities. The blood levels of all proteins studied were significantly higher in patients with unfavorable outcome (GOSE $\leq 4, n=28$ ) compared to those with favorable outcome (GOSE $\geq 5, n=60)(p \leq 0.001)$. Again, the ability of each biomarker for the detection of favorable outcome was evaluated when the protein reached $95-100 \%$ sensitivity. According to these criteria, the best performing protein was IL-10, with a 
TABLE 1 | Characteristics of the study patients.

\begin{tabular}{|c|c|c|c|c|c|c|c|c|}
\hline & \multicolumn{4}{|c|}{ TBI all severities } & \multicolumn{4}{|c|}{ Mild TBI } \\
\hline & \multicolumn{2}{|c|}{ Complete recovery } & \multicolumn{2}{|c|}{ Favorable outcome } & \multicolumn{2}{|c|}{ Complete recovery } & \multicolumn{2}{|c|}{ Favorable outcome } \\
\hline & GOSE 8 & GOSE 1-7 & GOSE 5-8 & GOSE 1-4 & GOSE 8 & GOSE 1-7 & GOSE 5-8 & GOSE 1-4 \\
\hline & $(n=25)$ & $(n=63)$ & $(n=60)$ & $(n=28)$ & $(n=25)$ & $(n=24)$ & $(n=45)$ & $(n=4)$ \\
\hline \multicolumn{9}{|l|}{ Age } \\
\hline Mean (SD) & $40.9(20.27)$ & $51.13(18.39)$ & $44(18.68)$ & $57.25(18.02)$ & $40.9(20.3)$ & $47.5(18.7)$ & $43.4(19.6)$ & $52.8(20.9)$ \\
\hline \multicolumn{9}{|l|}{ Gender } \\
\hline Male, n (\%) & $17(68)$ & $44(69.8)$ & $43(71.7)$ & $18(64.3)$ & $17(68)$ & $9(37.5)$ & $31(68.9)$ & $1(25)$ \\
\hline \multicolumn{9}{|l|}{ Marshall Grade, $n(\%)$} \\
\hline No visual pathology (grade 1) & $17(68)$ & $18(28.6)$ & $33(55)$ & $2(7.1)$ & $17(68)$ & $11(45.8)$ & 28 (62.3) & $0(0)$ \\
\hline Diffuse injury (grade 2) & $4(16)$ & $11(17.5)$ & $11(18.3)$ & $4(14.3)$ & $4(16)$ & $9(37.5)$ & $10(22.2)$ & $3(75)$ \\
\hline Diffuse injury with swelling (grade 3) & $0(0)$ & $1(1.6)$ & $0(0)$ & $1(3.6)$ & $0(0)$ & $0(0)$ & $0(0)$ & $0(0)$ \\
\hline Diffuse injury with shift (grade 4) & $0(0)$ & $0(0)$ & $0(0)$ & $0(0)$ & $0(0)$ & $0(0)$ & $0(0)$ & $0(0)$ \\
\hline Evacuated mass lesion (grade 5) & $1(4)$ & $22(34.9)$ & $9(15)$ & $14(50)$ & $1(4)$ & $1(4.2)$ & $2(4.4)$ & $0(0)$ \\
\hline Non evacuated mass lesion (Grade 6) & $3(12)$ & $11(17.5)$ & $7(11.7)$ & $7(25)$ & $3(12)$ & $3(12.5)$ & $5(11.1)$ & $1(25)$ \\
\hline \multicolumn{9}{|l|}{ Injury Severity Score (ISS), $n$ (\%) } \\
\hline Minor 1-8 & $16(64)$ & $13(20.6)$ & $27(45)$ & $2(7.1)$ & $16(64)$ & $10(41.7)$ & $25(55.6)$ & $1(25)$ \\
\hline Moderate 9-15 & $4(16)$ & $15(23.8)$ & $13(21.6)$ & $6(21.4)$ & $4(16)$ & $8(33.3)$ & $10(22.2)$ & $2(50)$ \\
\hline Serious 16-24 & $4(16)$ & $16(25.3)$ & $12(20)$ & $8(28.6)$ & $4(16)$ & $4(16.7)$ & $7(15.6)$ & $1(25)$ \\
\hline Severe 25-49 & $1(4)$ & $17(26.9)$ & $7(11.7)$ & 11 (39.3) & $1(4)$ & $2(8.3)$ & $3(6.7)$ & $0(0)$ \\
\hline Critical 50-74 & $0(0)$ & $1(1.6)$ & $1(1.7)$ & $0(0)$ & $0(0)$ & $0(0)$ & $0(0)$ & $0(0)$ \\
\hline Maximum 75 & $0(0)$ & $1(1.6)$ & $0(0)$ & $1(3.6)$ & $0(0)$ & $0(0)$ & $0(0)$ & $0(0)$ \\
\hline \multicolumn{9}{|l|}{ *Severity, $n$ (\%) } \\
\hline Very mild 1 & $1(4)$ & $0(0)$ & $1(1.7)$ & $0(0)$ & $1(4)$ & $0(0)$ & $1(2.2)$ & $0(0)$ \\
\hline Mild 2 & $23(92)$ & 27 (42.9) & $45(75)$ & 5 (17.9) & 23 (92) & $18(75)$ & $39(8.7)$ & $2(50)$ \\
\hline Moderate 3 & $0(0)$ & $12(19.1)$ & $7(11.7)$ & $5(17.9)$ & $0(0)$ & $4(16.6)$ & $3(6.7)$ & $1(25)$ \\
\hline Severe 4 & $1(4)$ & $10(15.9)$ & $5(8.2)$ & $6(21.4)$ & $1(4)$ & $1(4.2)$ & $1(2.2)$ & $1(25)$ \\
\hline Very severe 5 & $0(0)$ & $12(19.1)$ & $1(1.7)$ & $11(39.3)$ & $0(0)$ & $0(0)$ & $0(0)$ & $0(0)$ \\
\hline Unknown & - & $2(3.1)$ & $1(1.7)$ & $1(3.6)$ & $0(0)$ & $1(4.2)$ & $1(2.2)$ & $0(0)$ \\
\hline \multicolumn{9}{|l|}{ GCS, $n(\%)$} \\
\hline Mild 13-15 & $25(100)$ & $24(38.1)$ & $45(75)$ & $4(14.2)$ & 25 (100) & 24 (100) & 45 (100) & $4(100)$ \\
\hline Moderate 9-12 & $0(0)$ & $24(38.1)$ & $12(20)$ & $12(42.9)$ & $0(0)$ & $0(0)$ & $0(0)$ & $0(0)$ \\
\hline Severe 3-8 & $0(0)$ & 15 (23.8) & $3(5)$ & $12(42.9)$ & $0(0)$ & $0(0)$ & $0(0)$ & $0(0)$ \\
\hline \multicolumn{9}{|l|}{ Time from injury to blood sampling } \\
\hline Mean, hours (SD) & $6.2(5.7)$ & $9.9(6.1)$ & $9.8(6.1)$ & $12.3(6.6)$ & $6.2(4.8)$ & $12.9(5.7)$ & $9(10.3)$ & $14(4.6)$ \\
\hline
\end{tabular}

*Severity combined from GCS and duration of posttraumatic amnesia, see ref ${ }^{1}$.

sensitivity reaching $96 \%$ and specificity of $50 \%$. The proteins $\mathrm{H}-$ FABP and GFAP performed similarly, with sensitivities of $96 \%$ for both and specificities of $30 \%$ and $28 \%$, respectively (Table 4 ).

The proteins' performances were also evaluated when they were combined in panels and when they were combined with clinical parameters. Individual performances of clinical parameters are presented in Supplementary Table 2.

The best combination using two proteins was IL-10 and $\mathrm{H}$ FABP. This panel was capable of reaching $96 \%$ sensitivity and $58 \%$ specificity. This combination increased the specificity with 8 percentage points compared to the best single molecule IL- 10 . The best performing panel combining three proteins included IL-10, H-FABP, and GFAP. This panel managed to maintain the sensitivity at $96 \%$ and to increase the specificity up to $63 \%$ (Table 5).

The combination of individual proteins with clinical parameters improved the predictive ability compared to predictions using only protein biomarkers. Combining IL-10, the most specific protein, with patient's age and TBI severity reached $80 \%$ specificity with $96 \%$ sensitivity, which produces an increase in the specificity of 30 percentage points when comparing with the best single protein marker (Table 5).

\section{DISCUSSION}

Reliable early prediction of the patient's outcome in TBI can help clinicians in their decision-making and thereby optimize the care cost-effectively. Different blood biomarkers have previously been suggested as objective outcome predictor tools. This prospective, observational study of patients with acute TBI showed the potential benefits of using novel TBI biomarkers IL-10 and H-FABP but also previously studied biomarkers GFAP (13, 33), S100 $\beta$ (34), and NF-L (11, 
33, 35) as individual predictive biomarkers for promising outcome prediction; this also showed that models including previously known robust clinical predictors may further improve the accuracy.

According to the results presented in this manuscript we can highlight that blood biomarkers have a strong outcomepredictive capacity in patients with TBI and more importantly that the combination with other biomarkers or clinical parameters enhances this precision.

The present study has shown that, in mTBI patients, among all the tested proteins, H-FABP exhibits the best capacity in discriminating patients with complete and incomplete recovery. This protein was also selected among the most promising ones when the predictive capacity of panel of proteins was evaluated; the combination of GFAP, H-FABP, and NF-L reached a specificity value of $40 \%$ when the sensitivity was set at 95$100 \%$. Furthermore, as previously stated, inclusion of different clinical covariates showed to importantly augment the outcome prediction capacity of the proteins. Models including H-FABP, NF-L, and ISS yielded a specificity of $56 \%$

TABLE 2 | Performance of single proteins when differentiating between complete (GOSE 8) and incomplete (GOSE $\leq 7$ ) recovery in patients with $\mathrm{mTBI}$.

\begin{tabular}{lclcc}
\hline & $\begin{array}{c}\text { \% pAUC } \\
(\mathbf{9 5 \%} \mathbf{C l})\end{array}$ & Threshold & \%SP (95\% Cl) & $\begin{array}{c}\mathbf{9 5 - 1 0 0 ~ \% S E ~} \\
\mathbf{( 9 5 \% ~ C l )}\end{array}$ \\
\hline H-FABP & $0.2(0.0-0.7)$ & 44.9 & $4.0(0.0-12)$ & $100(100-100)$ \\
NF-L & $0.1(0.0-1.2)$ & 4.85 & $12(0.0-24.1)$ & $95.8(87.5-100)$ \\
S100 3 & $0.1(0.0-1.0)$ & 23.17 & $12(0.0-28.0)$ & $95.8(87.5-100)$ \\
IL-10 & $0.0(0.0-0.7)$ & - & $0.0(0-0)$ & $100(100-100)$ \\
GFAP & $0.0(0.0-0.6)$ & - & $0.0(0-0)$ & $100(100-100)$ \\
\hline
\end{tabular}

Biomarkers are shown according to their specificity obtained at 95-100\% sensitivity. pAUC, partial area under the curve; SP, specificity; SE, sensitivity; IL-10, interleukin 10; H-FABP, heart fatty-acid binding protein; GFAP, glial fibrillary acidic protein; NF-L, neurofilament light; $S 100 \beta$, S100 calcium-binding protein B. All threshold concentrations are in $\mathrm{pg} / \mathrm{mL}$ except for $\mathrm{H}$-FABP which is in $\mathrm{ng} / \mathrm{mL}$.
In regard to patients with TBIs of all severities, IL-10 has the best capacity to discriminate favorable and unfavorable outcome; however, similarly to the mTBI population, the specificities of all proteins studied remained $\leq 50 \%$ when studied in isolation. Based on these findings, we again studied the proteins in panels fixing the sensitivity at $95-100 \%$, which allowed us to find that the combination of GFAP, H-FABP, and IL-10 reached a specificity value of $63 \%$. Once again, the inclusion of clinical covariates drastically improved the results reaching a specificity of $80 \%$ when IL-10, age and TBI were combined together.

Briefly, the current results indicate that of all studied proteins $\mathrm{H}-\mathrm{FABP}$ has the best capacity to predict complete recovery and IL-10 to predict favorable outcome. In all two- and threebiomarker panels, either H-FABP and IL-10 were included. These markers have previously been shown efficient as CT scan triage tool for patients with mild TBI (22).

The protein H-FABP is a small cytoplasmic protein that leaks out from injured endothelial cells and neuronal cell bodies. It is a well-known myocardial infarction biomarker, and, even if it is not a TBI specific marker, increased levels have previously

TABLE 4 | Performance of single proteins when differentiating between favorable (GOSE 5-8) and unfavorable (GOSE 1-4) outcomes in all severity patients.

\begin{tabular}{|c|c|c|c|c|}
\hline & $\%$ pAUC $(95 \% \mathrm{Cl})$ & Threshold & $\%$ SP $(95 \%$ Cl) & $95-100 \%$ SE $(95 \% \mathrm{Cl})$ \\
\hline $\mathrm{IL}-10$ & $1.4(0.7-3.0)$ & 0.39 & $50.0(36.7-63.3)$ & 96.4 (89.3-100) \\
\hline $\mathrm{H}$-FABP & $1.1(0.6-2.7)$ & 4.31 & $30.0(18.3-41.7)$ & 96.4 (89.3-100) \\
\hline GFAP & $0.8(0.3-2.3)$ & 415 & $28.3(16.7-40.0)$ & $96.4(89.3-100)$ \\
\hline NFL & $0.5(0.2-4.4)$ & 5.47 & $10.0(3.3-18.3)$ & $100(100-100)$ \\
\hline $\mathrm{S} 100 \beta$ & $0.1(0-1.4)$ & 23.17 & $6.7(1.7-13.3)$ & 96.4 (89.3-100) \\
\hline
\end{tabular}

Biomarkers are shown in order according to their specificity obtained at 95-100\% sensitivity. Mann U, Mann-Whitney U-test; pAUC, partial area under the curve; SP, specificity; SE, sensitivity; IL-10, interleukin 10; H-FABP, heart fatty-acid binding protein; GFAP, glial fibrillary acidic protein; NF-L, neurofilament light; $S 100 \beta$, $S 100$ calcium-binding protein $B$. All threshold concentrations are in $\mathrm{pg} / \mathrm{mL}$ except for $\mathrm{H}$-FABP, which is in $\mathrm{ng} / \mathrm{mL}$.

TABLE 3 | Panels performed in patients with mTBI, including proteins (H-FABP, IL-10, GFAP, S100 $\beta$, and NF-L) or proteins and clinical parameters: Marshall grade, severity, injury severity score, and age.

\begin{tabular}{|c|c|c|c|c|c|}
\hline Panel & Markers cut-off & n GOSE 8 & n GOSE $<7$ & $\%$ SP (95\% CI) & $\%$ SE $(95 \%$ CI) \\
\hline \multirow[t]{2}{*}{2 Parameters (only proteins) } & H-FABP (6.26) & 25 & 24 & $40.0(20.0-60.0)$ & $95.8(87.5-100)$ \\
\hline & NF-L (15.9) & & & & \\
\hline \multirow[t]{3}{*}{3 Parameters (only proteins) } & H-FABP (5.01) & 25 & 24 & $44.0(24.0-64.0)$ & $95.8(87.5-100)$ \\
\hline & NF-L (13.46) & & & & \\
\hline & GFAP (2457.5) & & & & \\
\hline \multirow[t]{2}{*}{2 Parameters (proteins/clinical parameters) } & H-FABP (6.26) & 25 & 24 & $40.0(20.0-60.0)$ & $95.7(87.0-100)$ \\
\hline & NF-L (15.9) & & & & \\
\hline \multirow[t]{3}{*}{3 Parameters (proteins/clinical parameters) } & H-FABP (4.30) & 25 & 24 & $56.0(36.0-76.0)$ & $95.7(87.0-100)$ \\
\hline & NF-L (13.46) & & & & \\
\hline & Severity (2.5) & & & & \\
\hline
\end{tabular}

Complete recovery GOSE 8 and incomplete recovery GOSE $\leq 7$; SP, specificity; SE, sensitivity. All protein cut-off concentrations are in pg/mL except for $\mathrm{H}$-FABP, which is in ng/mL. 
TABLE 5 | Panels including only proteins (H-FABP, IL-10, GFAP, S100 $\beta$, and NF-L) or proteins and clinical parameters (Marshall grade, severity, injury severity score, age, and GCS).

\begin{tabular}{|c|c|c|c|c|c|}
\hline Panel & Markers cut-off & n GOSE $\geq 5$ & n GOSE $\leq 4$ & $\%$ SP (95\% Cl) & $\%$ SE $(95 \% \mathrm{Cl})$ \\
\hline \multirow[t]{2}{*}{2 Parameters (only proteins) } & IL-10 (0.38) & 60 & 28 & $58.3(45.0-71.7)$ & $96.4(89.3-100)$ \\
\hline & H-FABP (4.31) & & & & \\
\hline \multirow[t]{3}{*}{3 Parameters (only proteins) } & IL-10 (0.38) & 60 & 28 & $63.3(51.7-75.0)$ & $96.4(89.3-100)$ \\
\hline & H-FABP (4.31) & & & & \\
\hline & GFAP (145.13) & & & & \\
\hline \multirow[t]{2}{*}{2 Parameters (proteins/clinical parameters) } & NF-L (41.5) & 59 & 27 & $72.9(61-84.7)$ & $96.3(88.9-100)$ \\
\hline & Severity (2.5) & & & & \\
\hline \multirow[t]{3}{*}{3 Parameters (proteins/clinical parameters) } & IL-10 (0.44) & 59 & 27 & $79.7(69.5-89.8)$ & $96.3(88.9-100)$ \\
\hline & Age (61) & & & & \\
\hline & Severity (2.5) & & & & \\
\hline
\end{tabular}

Favorable outcome GOSE $\geq 5$ and unfavorable outcome GOSE $\leq 4$; SP, specificity; SE, sensitivity. All protein cut-off concentrations are in pg/mL except for H-FABP, which is in ng/mL.

been shown in patients with severe TBI and poor outcome (36-39). IL-10 or human cytokine synthesis inhibitory factor is a potent anti-inflammatory cytokine mainly produced by macrophages, B cells, and dendritic cells. Similarly, it is not a brain-specific marker, but the levels have also been shown to be increased in patients with severe TBI and poor outcome (40). Literature on the prognostic value of both H-FABP and IL10 is scarce. The previous reports on the outcome prediction ability of IL-10 after TBI are contradictory, though it has shown some potential in the prediction of mortality-the past studies have been very heterogenic in their methods (41). Intriguingly, the best-performing three-biomarker panel in discriminating patients with favorable and unfavorable outcome in patients with TBIs of all severities (GFAP, H-FABP, and IL-10) was the same that we have previously reported to be the best panel in detecting patients with CT-positive findings in the groups of patients with TBIs of all severities and patients with mTBIs without extracranial injuries (24). Because all these studies are from the same patient population, further studies should confirm if these combinations perform best also in other patients with acute TBI.

Several different pathophysiological processes can affect the outcome of TBI, such as apoptosis, blood brain barrier damage, and neuroinflammation (42). TBI is a complex pathophysiological disease where single markers may never be accurate enough for clinical applications (43). Combining biomarkers from different pathophysiological pathways has previously been shown to increase the overall accuracy $(16,24)$. Among other clinical parameters, such as age, Marshall grade, or ISS, we chose to include both the GCS score and TBI severity (an aggregate covariate) to the predictive models consisting of clinical covariates and biomarkers because we hypothesized that it would better reflect the importance of PTA in combination with the GCS score. As seen in the results, TBI severity is included more often in the predictive models than the GCS score alone. The prediction capacity of biomarkers is usually evaluated using the total AUC value; however, this entire value of ROC curve evaluates regions that usually are not relevant to clinical applications. Therefore, in order to avoid this drawback we decided to focus on pAUC, evaluating specificity values only when the sensitivity was fixed between 95 and 100\% (44).

The model selection method used in this manuscript, PanelomiX, has been shown to have several advantages over other already known selection methods, such as random forest, support vector machine or logistic regression. It has provided us the selection of best biomarkers specifying their optimal cut-off points (obtained by cross-validation). Obtained results are easy to interpret for the clinicians, which is another important advantage over other traditional black-box methods, and furthermore the prediction performances of panels obtained using PanelomiX tool are similar to that obtained with support vector machine among others.

This study has several limitations. Blood samples were collected within the first $24 \mathrm{~h}$ after trauma, which could be too late for the measurement of several biomarkers as S100 $\beta$ and GFAP $(24,45)$. The optimal biomarker panel is probably greatly dependent on both the time from injury and type of injury, and this is why further studies are necessary to clarify which biomarkers or biomarker combinations perform best at different points of time in different TBI populations. There is also some evidence that the clinical usability of biomarkers may depend on the age of the patient (46). Furthermore, the cohort used here included only 88 patients with TBI, making multivariate analysis of the molecules inconvenient according to the Monte Carlo study (47). The fairly small study population also increases the risk of over-fitting bias, which is why the results should be verified and validated in a larger cohort. Our study cohort included patients with TBI of all the severities where $56 \%$ had mTBI and 17\% had severe TBI. For the whole cohort, the results may be partly driven by the more severe cases of TBI due to their higher biomarker levels, and, on the other hand, our cases of mTBI were more severe than patients with mTBI as a whole 
since most of our cases had been admitted to neurosurgical ward. We chose to study patients with mTBI and TBIs of all severities independently because (i) patients with mTBI are a distinctive group of patients with specific diagnostic needs, and (ii) examining the outcome prediction ability in patients with all severities is important because initial severity of a TBI is not always clear due to possible confounding factors (such as intoxication, hypoglycemia, and neurological diseases).

Moreover, using GOSE as an outcome measure is a relatively insensitive way to detect subtle impairments in patients with mTBI or in TBI in general since it will miss many important and subtle deficits and it may be affected also by factors not directly related to the anatomical brain injury itself. The usability of IL-10 and $\mathrm{H}$-FABP should be studied using a higher number of patients with different clinical characteristics.

\section{CONCLUSION}

The novel proteins IL-10 and H-FABP in TBI diagnostics show promise in detecting patients with either favorable outcome or complete recovery following TBI. Combining levels of these proteins and NF-L with clinical covariates may assist in clinical decision-making at the emergency department and stratification for different monitoring and treatment algorithms.

\section{DATA AVAILABILITY STATEMENT}

The datasets analyzed in this article are not publicly available. Requests to access the datasets should be directed to leire.azurmendi@unige.ch.

\section{ETHICS STATEMENT}

The studies involving human participants were reviewed and approved by $68 / 180 / 2011$. The patients/participants provided their written informed consent to participate in this study.

\section{AUTHOR CONTRIBUTIONS}

LL, LA, and J-CS conceived and designed the study with critical contributions from OT and JP. OT, JP, AK, RT, H-RM, and JT recruited the patients and collected the data with critical contributions from IH. LL, LA, J-CS, HZ, and KB were responsible for analytical biomarker assessments. LL, LA, and J-CS conducted the statistical analyses. LL, LA, OT, JP, and J-CS drafted the manuscript. All authors substantially contributed to the revision of the manuscript. OT, VN, MG, PH, JP, and J-CS supervised the study. JP and J-CS take the responsibility for the paper as whole.

\section{FUNDING}

Dr. Posti has received funding from the Academy of Finland (Grant \#17379) and Government's Special Financial Transfer tied to academic research in Health Sciences (Finland). Dr. Posti has also received a grant from the Finnish Brain Foundation, a grant from the Emil Aaltonen Foundation, as well as a grant from the Maire Taponen Foundation.

\section{ACKNOWLEDGMENTS}

This work was partially funded by the European Commission under the 7th Framework Programme (FP7-270259-TBIcare), Academy of Finland (Grant \#17379) (JP), the Government's Special Financial Transfer tied to academic research in Health Sciences (Finland) (JP), the Emil Aaltonen Foundation sr (JP), the Finnish Brain Foundation sr (JP), the Maire Taponen Foundation (JP), the Integra EANS Research Grant (IH), the Academy of Medical Sciences/The Health Foundation Fellowship (VN), NIHR Research UK (through a Senior Investigator Award and the Cambridge Biomedical Research Centre) (DM), the Wallenberg Academy Fellowship and grants from the Swedish and European Research Councils (HZ), the Torsten Söderberg Professorship in Medicine, award by the Royal Swedish Academy of Sciences, and grants from the Swedish Research Council (KB). The authors thank our research nurses Patricia Bertenyi and Satu Honkala for their valuable contribution to this study.

\section{SUPPLEMENTARY MATERIAL}

The Supplementary Material for this article can be found online at: https:/www.frontiersin.org/articles/10.3389/fneur. 2020.00376/full\#supplementary-material

\section{REFERENCES}

1. Maas AIR, Menon DK, Adelson PD, Andelic N, Bell MJ, Belli A, et al. Traumatic brain injury: integrated approaches to improve prevention, clinical care, and research. Lancet Neurol. (2017) 16:987-1048. doi: 10.1016/S1474-4422(17)30371-X

2. Blyth BJ, Bazarian JJ. Traumatic alterations in consciousness: traumatic brain injury. Emergency Med Clin N Am. (2010) 28:571-94. doi: 10.1016/j.emc.2010.03.003

3. Cassidy JD, Boyle E, Carroll LJ. Population-based, inception cohort study of the incidence, course, and prognosis of mild traumatic brain injury after motor vehicle collisions. Arch Phys Med Rehabilit. (2014) 95:S27885. doi: 10.1016/j.apmr.2013.08.295

4. Thornhill S, Teasdale GM, Murray GD, McEwen J, Roy CW, Penny KI. Disability in young people and adults one year after head injury: prospective cohort study. BMJ. (2000) 320:1631-5. doi: 10.1136/bmj.320.7250.1631

5. McMahon P, Hricik A, Yue JK, Puccio AM, Inoue T, Lingsma HF, et al. Symptomatology and functional outcome in mild traumatic brain injury: results from the prospective TRACK-TBI study. J Neurotrauma. (2014) 31:2633. doi: $10.1089 /$ neu.2013.2984

6. Levin HS, Diaz-Arrastia RR. Diagnosis, prognosis, and clinical management of mild traumatic brain injury. Lancet Neurol. (2015) 14:506-17. doi: 10.1016/S1474-4422(15)00002-2

7. Oliveira CO, Ikuta N, Regner A. Outcome biomarkers following severe traumatic brain injury. Rev Bra Terap Intensiva. (2008) 20:411-21. doi: 10.1590/S0103-507X2008000400015 
8. Kulbe JR, Geddes JW. Current status of fluid biomarkers in mild traumatic brain injury. Exp Neurol. (2016) 3:33452. doi: 10.1016/j.expneurol.2015.05.004

9. Thelin EP, Nelson DW, Bellander BM. A review of the clinical utility of serum S100B protein levels in the assessment of traumatic brain injury. Acta Neuroch. (2017) 159:209-25. doi: 10.1007/s00701-016-3046-3

10. Wiesmann M, Steinmeier E, Magerkurth O, Linn J, Gottmann D, Missler U. Outcome prediction in traumatic brain injury: comparison of neurological status, CT findings, and blood levels of S100B and GFAP. Acta Neurol Scand. (2010) 121:178-85. doi: 10.1111/j.1600-0404.2009.01196.x

11. Al Nimer F, Thelin E, Nystrom H, Dring AM, Svenningsson A, Piehl F, et al. Comparative assessment of the prognostic value of biomarkers in traumatic brain injury reveals an independent role for serum levels of neurofilament light. PLoS ONE. (2015) 10:e0132177. doi: 10.1371/journal.pone. 0132177

12. Shahim P, Gren M, Liman V, Andreasson U, Norgren N, Tegner $Y$, et al. Serum neurofilament light protein predicts clinical outcome in traumatic brain injury. Sci Rep. (2016) 6:36791. doi: 10.1038/srep36791

13. Takala RS, Posti JP, Runtti H, Newcombe VF, Outtrim J, Katila AJ, et al. Glial fibrillary acidic protein and ubiquitin C-terminal hydrolase-L1 as outcome predictors in traumatic brain injury. World Neurosurg. (2016) 87:820. doi: 10.1016/j.wneu.2015.10.066

14. Lagerstedt L, Egea-Guerrero JJ, Rodriguez-Rodriguez A, Bustamante A, Montaner J, El Rahal A, et al. Early measurement of interleukin-10 predicts the absence of CT scan lesions in mild traumatic brain injury. PLoS ONE. (2018) 13:e0193278. doi: 10.1371/journal.pone.0193278

15. Lagerstedt L, Egea-Guerrero JJ, Bustamante A, Montaner J, RodriguezRodriguez A, El Rahal A, et al. H-FABP: A new biomarker to differentiate between CT-positive and CT-negative patients with mild traumatic brain injury. PLoS ONE. (2017) 12:e0175572. doi: 10.1371/journal.pone. 0175572

16. Robin X, Turck N, Hainard A, Lisacek F, Sanchez JC, Muller M. Bioinformatics for protein biomarker panel classification: what is needed to bring biomarker panels into in vitro diagnostics? Exp Rev Proteom. (2009) 6:675-89. doi: 10.1586/epr.09.83

17. Azurmendi L, Sarrafzadeh A, Tiberti N, Kapandji N, Sanchez-Peña P, Degos V, et al. Infection prediction for aneurysmal subarachnoid hemorrhage patients at hospital admission: combined panel of serum amyloid A and clinical parameters. J Transl Sci. (2017) 3:1-5. doi: 10.15761/JTS.1000184

18. Hainard A, Tiberti N, Robin X, Lejon V, Ngoyi DM, Matovu E, et al. A combined CXCL10, CXCL8 and H-FABP panel for the staging of human African trypanosomiasis patients. PLoS Negl Trop Dis. (2009) 3:e459. doi: 10.1371/journal.pntd.0000459

19. Tiberti N, Matovu E, Hainard A, Enyaru JC, Lejon V, Robin X, et al. New biomarkers for stage determination in Trypanosoma brucei rhodesiense sleeping sickness patients. Clin Transl Med. (2013) 2:1. doi: 10.1186/2001-1326-2-1

20. Calderon-Santiago M, Priego-Capote F, Turck N, Robin X, Jurado-Gamez B, Sanchez JC, et al. Human sweat metabolomics for lung cancer screening. Analyt Bioanalyt Chem. (2015) 407:5381-92. doi: 10.1007/s00216-015-8700-8

21. Turck N, Vutskits L, Sanchez-Pena P, Robin X, Hainard A, Gex-Fabry M, et al. A multiparameter panel method for outcome prediction following aneurysmal subarachnoid hemorrhage. Inten Care Med. (2010) 36:10715. doi: 10.1007/s00134-009-1641-y

22. Lagerstedt L, Egea-Guerrero JJ, Bustamante A, Rodriguez-Rodriguez A, El Rahal A, Quintana-Diaz M, et al. Combining H-FABP and GFAP increases the capacity to differentiate between CT-positive and CTnegative patients with mild traumatic brain injury. PLoS ONE. (2018) 13:e0200394. doi: 10.1371/journal.pone.0200394

23. Shan R, Szmydynger-Chodobska J, Warren OU, Mohammad F, Zink BJ, Chodobski A. A new panel of blood biomarkers for the diagnosis of mild traumatic brain injury/concussion in adults. J Neurotrauma. (2016) 33:4957. doi: 10.1089/neu.2014.3811

24. Posti JP, Takala RS, Lagerstedt L, Dickens AM, Hossain I, Mohammadian $\mathrm{M}$, et al. Correlation of blood biomarkers and biomarker panels with traumatic findings on computed tomography after traumatic brain injury. $J$ Neurotrauma. (2019) 36:2178-89. doi: 10.1089/neu.2018.6254
25. Woodcock T, Morganti-Kossmann MC. The role of markers of inflammation in traumatic brain injury. Front Neurol. (2013) 4:18. doi: 10.3389/fneur.2013.00018

26. Thelin E, Al Nimer F, Frostell A, Zetterberg H, Blennow K, Nystrom $\mathrm{H}$, et al. A serum protein biomarker panel improves outcome prediction in human traumatic brain injury. J Neurotrauma. (2019) 36:285062. doi: $10.1089 /$ neu.2019.6375

27. NICE. $<$ Head-injury-assessment-and-early-management-pdf-351097555954 93.pdf $>$. NICE (2019).

28. Teasdale GM, Pettigrew LE, Wilson JT, Murray G, Jennett B. Analyzing outcome of treatment of severe head injury: a review and update on advancing the use of the glasgow outcome scale. J Neurotrauma. (1998) 15:587-97. doi: 10.1089/neu.1998.15.587

29. Baker SP, O’Neill B, Haddon W Jr., Long WB. The injury severity score: a method for describing patients with multiple injuries and evaluating emergency care. J Trauma. (1974) 14:187-96. doi: 10.1097/00005373-197403000-00001

30. Lawrence FM, Sharon Bowers M, Melville RK, Marjan van Berkum C, Howard $\mathrm{ME}$, John AJ, et al. A new classification of head injury based on computerized tomography. J Neurosurg. (1991) 75:S14-20. doi: 10.3171/sup.1991.75. 1s.0s 14

31. Teasdale G, Jennett B. Assessment of coma and impaired consciousness. A practical scale. Lancet. (1974) 2:81-4. doi: 10.1016/S0140-6736(74)91639-0

32. Robin X, Turck N, Hainard A, Tiberti N, Lisacek F, Sanchez J-C, Müller M. PanelomiX: A threshold-based algorithm to create panels of biomarkers. Transl Proteom. (2013) 1:57-64. doi: 10.1016/j.trprot.2013.04.003

33. Hossain I, Mohammadian M, Takala SK, Tenovuo O, Lagerstedt L, AlaSeppala H, et al. Early levels of glial fibrillary acidic protein and neurofilament light protein in predicting the outcome of mild traumatic brain injury. $J$ Neurotrauma. (2019) 36:1551-60. doi: 10.1089/neu.2018.5952

34. Thelin EP, Nelson DW, Bellander BM. Secondary peaks of S100B in serum relate to subsequent radiological pathology in traumatic brain injury. Neurocrit Care. (2014) 20:217-29. doi: 10.1007/s12028-013-9916-0

35. Shahim P, Zetterberg H, Tegner Y, Blennow K. Serum neurofilament light as a biomarker for mild traumatic brain injury in contact sports. Neurology. (2017) 88:1788-94. doi: 10.1212/WNL.0000000000003912

36. Walder B, Robin X, Rebetez MM, Copin JC, Gasche Y, Sanchez JC, et al. The prognostic significance of the serum biomarker heart-fatty acidic binding protein in comparison with s100b in severe traumatic brain injury. J Neurotrauma. (2013) 30:1631-7. doi: 10.1089/neu. 2012.2791

37. Zimmerman AW, Veerkamp JH. New insights into the structure and function of fatty acid-binding proteins. Cell Mol Life Sci. (2002) 59:1096116. doi: 10.1007/s00018-002-8490-y

38. Veerkamp JH, Paulussen RJ, Peeters RA, Maatman RG, van Moerkerk HT, van Kuppevelt. TH. Detection, tissue distribution and (sub)cellular localization of fatty acid-binding protein types. Mol Cell Biochem. (1990) 98:11-8. doi: 10.1007/978-1-4615-3936-0_2

39. Pelsers MM, Hanhoff T, Van der Voort D, Arts B, Peters M, Ponds $\mathrm{R}$, et al. Brain- and heart-type fatty acid-binding proteins in the brain: tissue distribution and clinical utility. Clin Chem. (2004) 50:156875. doi: 10.1373/clinchem.2003.030361

40. Werhane ML, Evangelista ND, Clark AL, Sorg SF, Bangen KJ, Tran $\mathrm{M}$, et al. Pathological vascular and inflammatory biomarkers of acute- and chronic-phase traumatic brain injury. Concussion. (2017) 2:CNC30. doi: 10.2217/cnc-2016-0022

41. Garcia JM, Stillings SA, Leclerc JL, Phillips H, Edwards NJ, Robicsek SA, et al. Role of interleukin-10 in acute brain injuries. Front Neurol. (2017) 8:244. doi: 10.3389/fneur.2017.00244

42. Stocchetti N, Zanier ER. Chronic impact of traumatic brain injury on outcome and quality of life: a narrative review. Crit Care. (2016) 20:148. doi: 10.1186/s13054-016-1318-1

43. North SH, Shriver-Lake LC, Taitt CR, Ligler FS. Rapid analytical methods for on-site triage for traumatic brain injury. Ann Rev Anal Chem. (2012) 5:35-56. doi: 10.1146/annurev-anchem-062011-143105

44. McClish DK, Analyzing a portion of the ROC curve. Med Decision Making. (1989) 9:190-5. doi: 10.1177/0272989X8900900307 
45. Thelin EP, Zeiler FA, Ercole A, Mondello S, Buki A, Bellander BM, et al. Serial sampling of serum protein biomarkers for monitoring human traumatic brain injury dynamics: a systematic review. Front Neurol. (2017) 8:300. doi: 10.3389/fneur.2017.00300

46. Iverson GL, Preethi R, Posti J, Tenovuo O, Ohman J, Zetterberg H, et al. Serum neurofilament light is elevated differentially in older adults with uncomplicated mild traumatic brain injuries. J Neurotrauma. (2019) 36:24006. doi: $10.1089 /$ neu.2018.6341

47. Peduzzi P, Concato J, Kemper E, Holford TR, Feinstein AR. A simulation study of the number of events per variable in logistic regression analysis. J Clin Epidemiol. (1996) 49:1373-9. doi: 10.1016/S0895-4356(96)0 0236-3
Conflict of Interest: The authors declare that the research was conducted in the absence of any commercial or financial relationships that could be construed as a potential conflict of interest.

Copyright (c) 2020 Lagerstedt, Azurmendi, Tenovuo, Katila, Takala, Blennow, Newcombe, Maanpää, Tallus, Hossain, Gils, Menon, Hutchinson, Zetterberg, Posti and Sanchez. This is an open-access article distributed under the terms of the Creative Commons Attribution License (CC BY). The use, distribution or reproduction in other forums is permitted, provided the original author(s) and the copyright owner(s) are credited and that the original publication in this journal is cited, in accordance with accepted academic practice. No use, distribution or reproduction is permitted which does not comply with these terms. 